\title{
Ground- and satellite-based evidence of the biophysical mechanisms behind the greening Sahel
}

\author{
MARTIN BRANDT ${ }^{1}$, CHEIKH MBOW ${ }^{2,3}$, ABDOUL A. DIOUF ${ }^{4,5}$, ALEIXANDREVERGER ${ }^{6,7}$, \\ CYRUS SAMIMI ${ }^{1,8}$ and RASMUS FENSHOLT ${ }^{9}$ \\ ${ }^{1}$ Institute of Geography, University of Bayreuth, 95440 Bayreuth, Germany, ${ }^{2}$ Science Domain 6, ICRAF (World Agroforestry \\ Center), 00100 Nairobi, Kenya, ${ }^{3}$ Institut des Sciences de l'Environnement, Université Cheikh Anta Diop, BP 5005 Dakar, Senegal, \\ ${ }^{4}$ Centre de Suivi Ecologique, BP 15532 Dakar-Fann, Senegal, ${ }^{5}$ Campus Arlon Environnement, Université de Liege, Liege, Belgique, \\ ${ }^{6}$ Global Ecology Unit, CREAF, Cerdanyola del Vallès, E-08193 Catalonia, Spain, ${ }^{7}$ UMR 1114, INRA-EMMAH, Site Agroparc, \\ F-84914 Avignon, France, ${ }^{8}$ BAYCEER, University of Bayreuth, 95440 Bayreuth, Germany, ${ }^{9}$ Department of Geosciences and \\ Natural Resource Management, University of Copenhagen, 1350 Copenhagen, Denmark
}

\begin{abstract}
After a dry period with prolonged droughts in the 1970s and 1980s, recent scientific outcome suggests that the decades of abnormally dry conditions in the Sahel have been reversed by positive anomalies in rainfall. Various remote sensing studies observed a positive trend in vegetation greenness over the last decades which is known as the re-greening of the Sahel. However, little investment has been made in including long-term ground-based data collections to evaluate and better understand the biophysical mechanisms behind these findings. Thus, deductions on a possible increment in biomass remain speculative. Our aim is to bridge these gaps and give specifics on the biophysical background factors of the re-greening Sahel. Therefore, a trend analysis was applied on long time series (1987-2013) of satellite-based vegetation and rainfall data, as well as on ground-observations of leaf biomass of woody species, herb biomass, and woody species abundance in different ecosystems located in the Sahel zone of Senegal. We found that the positive trend observed in satellite vegetation time series $(+36 \%)$ is caused by an increment of in situ measured biomass $(+34 \%)$, which is highly controlled by precipitation $(+40 \%)$. Whereas herb biomass shows large inter-annual fluctuations rather than a clear trend, leaf biomass of woody species has doubled within 27 years $(+103 \%)$. This increase in woody biomass did not reflect on biodiversity with 11 of 16 woody species declining in abundance over the period. We conclude that the observed greening in the Senegalese Sahel is primarily related to an increasing tree cover that caused satellite-driven vegetation indices to increase with rainfall reversal.
\end{abstract}

Keywords: biodiversity, biomass monitoring, degradation, greening, Sahel, vegetation change

Received 19 August 2014; revised version received 5 November 2014 and accepted 8 November 2014

\section{Introduction}

The West African Sahel has often been acclaimed as a hot spot of global environmental and climate change. During the 1970s and 1980s, droughts and a rapid and strong decline in annual precipitation caused a considerable dying of trees (Tappan et al., 2004) and satellite data showed exceptionally low greenness values in the Sahelian zone (Anyamba \& Tucker, 2005). Hence, many scientists flagged large areas of the Sahel as irreversibly degraded land (Ayoub, 1998; Dregne, 2002). However, since the 1990s, rainfall has been increasing again and satellite-measured greenness values have increased accordingly (Herrmann et al., 2005). The observed increment in vegetation greenness is steady and continues until today, hence called the (re-)greening Sahel phenomenon (Hickler et al., 2005; Olsson et al., 2005; Fensholt et al., 2012). Within the

Correspondence: Martin Brandt, tel. +49-921-554636, fax +49-921552314, e-mail: martin.brandt@mailbox.org past decade, a host of remote sensing studies using satellite time series has proven the existence of the positive vegetation anomalies in the last decades, contradicting the theories of irreversible degradation (Prince et al., 1998; Anyamba \& Tucker, 2005; Fensholt et al., 2013).

Scientists interpreted the observed positive trend in Normalized Difference Vegetation Index (NDVI) - a spectral index using red and infrared satellite bands to detect photosynthetic vigor - as an increase in biomass production. However, due to a lack of adequate ground studies, such deductions remain speculative and need to be validated. Many authors agree on the importance of increased rainfall as the main driver of the change (Hickler et al., 2005; Seaquist et al., 2009; Huber et al., 2011; Anyamba et al., 2014). Moreover, some efforts have been made to better understand the underlying factors beyond rainfall, i.e. soil types and human influence (Brandt et al., 2014a,b; Horion et al., 2014; Rasmussen et al., 2014), but results were 
deficient in including spatial heterogeneity and longterm in situ vegetation data. To our knowledge, no studies combined tree and herb data to analyze NDVI and rainfall variability over a long period and at a regional scale. Recent studies work generally either on the tree (Rasmussen et al., 2011) or on the herbaceous cover (Mbow et al., 2013; Dardel et al., 2014a,b) and remain at a short temporal scale (Fensholt et al., 2006; Mbow et al., 2013) or at a local spatial scale (Miehe et al., 2010; Brandt et al., 2014c). Another neglected aspect of the Sahel biophysical assessment is the relative importance of species dynamics, as the greening does not necessarily mean an increase in species richness. Only recently, few publications have tracked back the biodiversity evolution as response to both climate and productivity in the Sahel. They detected an apparent shift to more arid woody species (Hiernaux et al., 2009a; Gonzalez et al., 2012; Herrmann \& Tappan, 2013) and herb species with adapting capacities to grazing pressure and intra-annual rainfall variability (Mbow et al., 2013).

Studies relating Sahelian biomass observations to satellite data date back to the early 1980s (Tucker et al., 1983) and continue until today, with a range of scales and scopes (Tucker et al., 1985; Diallo et al., 1991; Diouf \& Lambin, 2001; Fensholt et al., 2006; Dardel et al., 2014b). Contradictions between satellite and ground-based assessment of land degradation were however often reported (Rasmussen et al., 2006). It is therefore important to assess land dynamics by combining various sources of information from satellite products to in situ measured biophysical vegetation parameters. So far, success in combining methods for vegetation trend analysis has been relatively limited because the process of obtaining field evidence on biomass dynamics is a cumbersome task and only rarely conducted in the Sahel.

The long-term biomass data collected by the Centre de Suivi Ecologique (CSE) from 1987 to 2013 in Senegal are unique for the Sahel and well suited for disentangling the influence of herb biomass vs. leaf biomass of woody species on the long-term NDVI trends. Our hypothesis in this study is that trees better depict the rainfall memory of a landscape as compared to the short-term response of the herbaceous cover.

The overall objective is to understand and quantify the inter-relationship between satellite spectral index, rainfall, and biomass production, and how long-term disaggregated vegetation in situ data could help untangling the relative importance of trees and herbs on the regional vegetation trends from 1987 to 2013. The specific objectives of this study are threefold: (1) assess the differential role of herb biomass and leaf biomass of woody species on long-term satellite greenness trends; (2) analyze the spatial and temporal variability of leaf biomass and biodiversity of woody species; and (3) highlight the importance of local-scale vegetation characteristics in analyzing regional NDVI trends in the Sahel.

\section{Materials and methods}

\section{Study area}

Located in West Africa, Senegal's relief is generally flat with elevations below $50 \mathrm{~m}$ on nearly $75 \%$ of its territory $\left(196722 \mathrm{~km}^{2}\right)$. Most of the landscape consists of peneplains crossed by an extensive valley network. Like most of the Sahelian countries, Senegal has a tropical climate characterized by a unimodal rainfall regime. Annual rainfall fluctuates on average between 250 and $1200 \mathrm{~mm}$, thus displaying an increasing gradient of rainfall from north to south.

The study sites are located in the Sahelian and northern Sahelo-Sudanian zone of Senegal (Fig. 1) and reflect areas of apparent greening (Herrmann et al., 2005; Anyamba et al., 2014). Anthropogenic influence is present (i.e. grazing, cutting), but limited (i.e. no cultivation, distance to villages) and 23 sites provide biomass observations from 1987 to 2013 , whereas 41 sites give evidence on the abundance of woody species between 1983 and 2013 (Fig. 1). Five classes reflect spatial variability regarding human influence, soil type, annual rainfall, and species composition (see CSE, 1996; Sagna, 2007; Tappan et al., 2004; Table 1 and Appendix S1):

1. Sandy Ferlo: This northern Sahelian region with a dry season from November to May consists of deep sandy soils with a pseudo-steppe. It has a sparse woody vegetation (5\% tree cover), and human influence is mainly grazing and small-scale cropping.

2. Ferruginous Ferlo: A shrub savannah with Sahelian rainfall regime and shallow ferruginous and lateritic soils is dominated by a moderately dense tree cover (17\%). Like the Sandy Ferlo, this silvo-pastoral region is mainly used for livestock herding by Fulani pastoralists and the dry season is from November to May.

3. Boundou: With a moderately dense tree cover (19\%), shallow soils, and a dry season from November to May, this tree savannah has little agricultural potential. It is the least populated region of Senegal and constitutes a vast grazing land.

4. Eastern Saloum: Ferruginous tropical soils in this southern Sahelian and Sahelo-Sudanian area are extensively cultivated by humans, but also protected and uncultivated areas exist (13\% tree cover). The dry season lasts from November to April.

5. Tamba: Study sites in the Tamba region are located in the southern Sahelian and border the Sahelo-Sudanian zone. The dry season lasts from November to April and high annual rainfall leads to dense woodland (32\%) on weakly leached ferruginous tropical soils with major human activities and protected forests. 


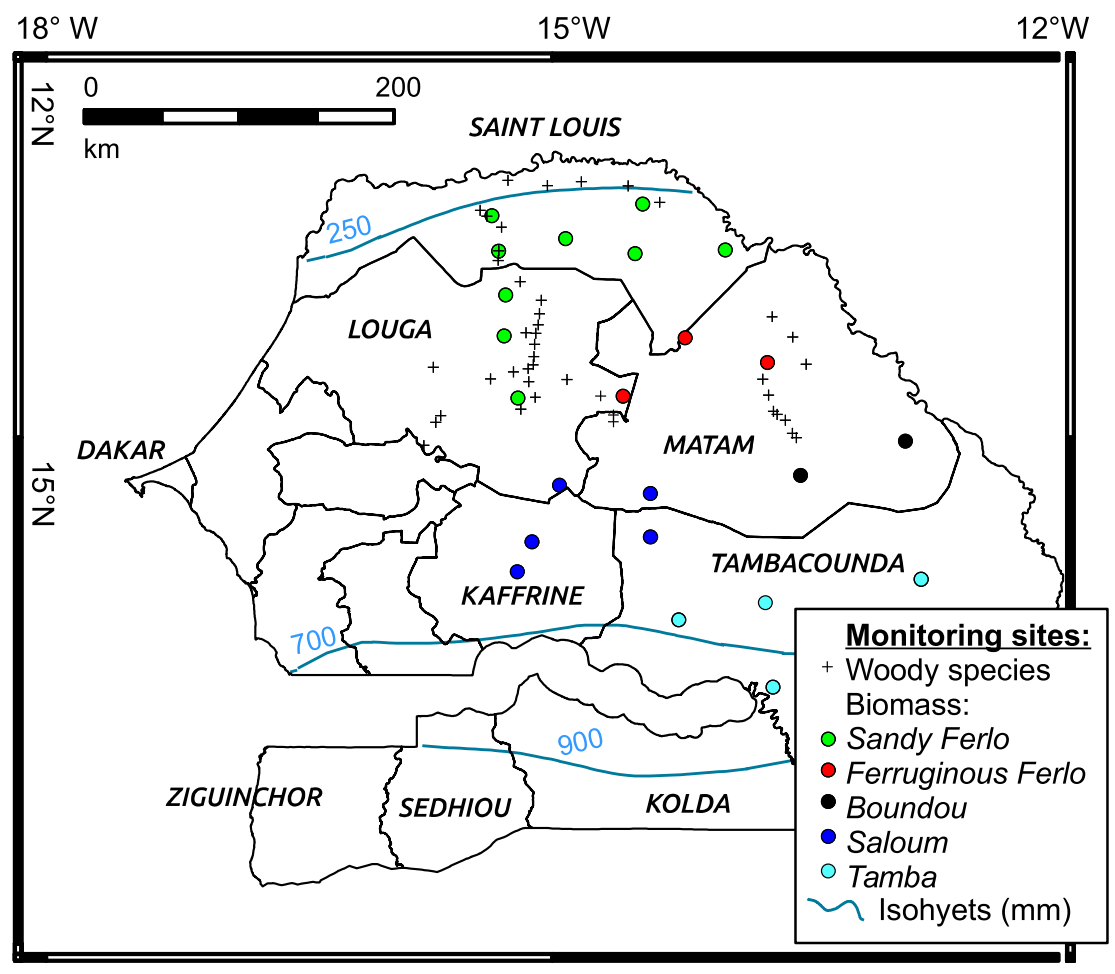

Fig. 1 Location of the woody species and biomass monitoring sites in Senegal. The isohyets are based on rain gauges. More information on the regions can be found in Tappan et al. (2004), Sagna (2007) and Table 1.

\section{Satellite vegetation data (NDVI)}

Normalized Difference Vegetation Index is a robust proxy to measure vegetation greenness by means of Earth observation (Tucker et al., 1985). We used a combination of high-quality Long-term Data Record (LTDR), Advanced Very High
Resolution Radiometer (AVHRR), and SPOT-Vegetation (VGT) NDVI data to obtain a decadal (10-day) time series from 1987 to 2013 (AVHRR ranges from 1987 to 1999 and VGT from 1998 to 2013) with a spatial resolution of approximately $5 \mathrm{~km}$ (Fensholt et al., 2009; Beck et al., 2011). Both datasets were filtered using quality flags to create a smooth time line. Data for

Table 1 Mean values of the biomass monitoring sites which are shown in Fig. 1. Rainfall is provided by Tropical Application of Meteorology using SATellite (TAMSAT)

\begin{tabular}{|c|c|c|c|c|c|c|}
\hline Region & $\begin{array}{l}\text { Annual } \\
\text { rainfall } \\
(\mathrm{mm})\end{array}$ & $\begin{array}{l}\text { Leaf } \\
\text { biomass } \\
\left(\mathrm{kg} \mathrm{ha}^{-1}\right)\end{array}$ & $\begin{array}{l}\text { Herb } \\
\text { biomass } \\
\left(\mathrm{kg} \mathrm{ha}^{-1}\right)\end{array}$ & $\begin{array}{l}\text { Tree } \\
\text { cover } \\
\%\end{array}$ & Dominant woody species & Human activities \\
\hline Sandy Ferlo & 219 & 440 & 970 & 5 & $\begin{array}{l}\text { Pseudo-steppe: Acacia raddiana, Balanites aegyptiaca, } \\
\text { Sclerocarya birrea, Adansonia digitata, Guiera } \\
\text { senegalensis, Boscia senegalensis }\end{array}$ & $\begin{array}{l}\text { Small-scale } \\
\text { cropping, pasture }\end{array}$ \\
\hline $\begin{array}{l}\text { Ferruginous } \\
\text { Ferlo }\end{array}$ & 273 & 1188 & 698 & 17 & $\begin{array}{l}\text { Shrub savannah: Pterocarpus lucens, B. aegyptiaca, } \\
\text { B. senegalensis, Adenium obesum, Grewia bicolor, } \\
\text { Combretum glutinosum }\end{array}$ & Pasture \\
\hline Boundou & 355 & 740 & 1554 & 19 & $\begin{array}{l}\text { Tree savannah: P. lucens, Sterculia setigera, } \\
\text { C. glutinosum, B. aegyptiaca, Acacia macrostachya }\end{array}$ & Pasture \\
\hline Saloum & 356 & 1019 & 2427 & 13 & $\begin{array}{l}\text { Tree savannah: S. setigera, C. glutinosum, Lannea } \\
\text { acida, S. birrea, G. bicolor, A. macrostachya }\end{array}$ & $\begin{array}{l}\text { Extensive cropping, } \\
\text { pasture, } \\
\text { agroforestry }\end{array}$ \\
\hline Tamba & 438 & 2306 & 2313 & 32 & $\begin{array}{l}\text { Woodland: C. glutinosum, S. setigera, Bombax } \\
\text { costatum, Cordyla pinnata, A. macrostachya, } \\
\text { Hexanolobus monopetalus }\end{array}$ & $\begin{array}{l}\text { Extensive cropping, } \\
\text { agroforestry, } \\
\text { fallows, pasture }\end{array}$ \\
\hline
\end{tabular}


the year 1994 were masked due to insufficient quality related to sensor orbital drift. Due to the varying calibration of the AVHRR and VGT sensors, a pixel-wise linear regression was applied to the overlapping years (1998 and 1999) and AVHRR pixels were adjusted to the newer VGT sensor, creating a consistent time series over 27 years. More information on the datasets and the processing can be found in Brandt et al. (2014a).

\section{Rainfall data}

Tropical Application of Meteorology using SATellite (TAMSAT) rainfall estimates are available for the period 1987-2013 with a high spatial $\left(0.0375^{\circ}\right)$ and temporal (10 days) resolution for the African continent. The product is derived from Meteosat thermal infrared channels with algorithms recognizing convective storm clouds and calibrated with groundbased synoptic rain gauge data (Maidment et al., 2013). TAMSAT provides an estimation of rainfall trends, even though the algorithm tends to underestimate high rainfall events, which explains the generally too low annual sums, as compared to rain gauges (Dardel et al., 2014a). Despite this limitation, the high spatial resolution of this dataset allows more detailed analyses of spatial variability as compared to other coarse resolution blended satellite/gauge precipitation datasets covering the full period of analysis, for example, Global Precipitation Climatology Center (GPCC), Global Precipitation Climatology Project (GPCP), Climate Prediction Center (CPC), and Merged Analysis of Precipitation (CMAP). The gap in September 2006 was filled with Tropical Rainfall Measurement Mission (TRMM) data (Huffman et al., 2007).

\section{Ground-based biomass estimations}

Biomass data are derived from the CSE database. Leaf biomass of woody species and herbaceous biomass were collected each year at the end of the growing season since 1987 (except 2004). Both were measured independently and total biomass was calculated by summing leaf and herb biomass for each year. The collection was performed by a stratified sampling and a circular systematic inventory based on $1 \mathrm{~km}$ line transect, respectively, for herbaceous and woody strata.

For herb sampling, each meter of the transect was classified in a three class production level classification (low, middle, and high production). Through these three levels, 35-100 weighed samples were randomly collected from $1 \mathrm{~m}^{2}$ quadrats, depending on the heterogeneity of the site. In a second resampling step, three $200 \mathrm{~g}$ samples were collected from the mixed samples of each production level and dried in an oven. The weighted sum of the herbaceous dry matter production rate multiplied by the average green weight for the three production levels provides the total herbaceous biomass production of each site.

Trees and shrubs were surveyed using four quadrats of up to one hectare, which were centered at 200,400, 600, and $800 \mathrm{~m}$. Woody production of the most representative species was estimated by allometric relationships $\left(P=a \times C^{b}\right)$, relating trunk circumference $(C)$ with typical individual production values $(P)$ using $a$ and $b$ parameters. These relationships have been established for a range of Sahelian tree and shrub species (Diallo et al., 1991; Diouf \& Lambin, 2001) after works of Cissé (1980) and Hiernaux (1980). Leaf biomass of 10 branches for each species was weighed and one $200 \mathrm{~g}$ sample collected for drying. Thereafter, woody production of individuals was calibrated by the ratio of leaf dry-weight, divided by standardized branch values to get an estimation of the woody leaf production. Here, the sum of the leaf production of all considered woody species was used. Tree cover was estimated between 1998 and 2013 and averaged over this period. It was measured for all studied species in percentage of $3 \times 3 \mathrm{~km}$ site area covered by the canopy of trees and shrubs.

\section{Trend analysis}

Tropical Application of Meteorology using SATellite (TAMSAT) and NDVI pixels overlaying the 23 biomass monitoring sites were extracted and rainfall and NDVI were summed to annual integrals. To test for significant trends over the studied period, a linear regression was conducted pixel-wise, with time as explanatory and annually summed NDVI, rainfall or biomass as response variable. The resulting slope $(b)$ represents the change of the corresponding unit per year. To obtain relative change in percent, the slope was multiplied by the number of years and divided by the long-term mean. The statistical significance $(p)$ of the linear trend was evaluated. A Pearson's correlation $(r)$ was applied as a measurement for fluctuations along the regression line, with an increasing interannual variability from 1 to 0 .

\section{Botanic inventory of woody species}

An inventory of woody species was conducted in 1983 by the US Geological Survey (USGS) and 2013 by the authors at 41 sites distributed over the Sandy and Ferruginous Ferlo, located in the proximity to the biomass monitoring sites. The abundance for tree (height $>4 \mathrm{~m}$ ) and shrub (height $<4 \mathrm{~m}$ ) species within open plots (2-4 ha) was rated separately in five abundance categories: (5) very common, (4) common, (3) present, (2) less common, and (1) rare. The methodology is easy to reproduce and provides a unique long-term overview of the abundance of species at the sites. More detailed information can be found in Herrmann \& Tappan (2013). The abundance values were summed over all sites in the Sandy and Ferruginous Ferlo regions for the years 1983 and 2013 to derive an overall estimate of the abundance of species for each region and year. A positive (negative) change in the abundance of species between 1983 and 2013 was considered as an increase (decrease) in the abundance occurrence if it represents more than $15 \%$ of the total abundance value. Otherwise, the abundance of the species is considered to be stable. Only species having a richness class higher than 1 at more than three sites for a particular region/year were considered to assess the change. The same species are used in both Sandy and Ferruginous Ferlo regions for change analysis (16 in total). 


\section{Results}

Inter-relationship between rainfall, biomass, and NDVI

A fairly high correlation between annual NDVI and total biomass (leaf + herb biomass) is shown in Fig. 2 $(r=0.76)$. This indicates that both years of high and low biomass observations are sufficiently captured by the spectral index. A clear linear cross-ecosystem relation is hampered by the saturation of NDVI in densely vegetated areas of the northern Sahelo-Sudanian zone (Olsson et al., 2005), and scattering is apparent in all the regions.

Furthermore, a high consistency can be observed between annual NDVI and annual precipitation (Fig. 2) $(r=0.86)$, confirming the strong relationship between vegetation greenness and rainfall. The highest correlation is found in the Sahel zone (Sandy and Ferruginous Ferlo, red and green points in Fig. 2) with most of the rain falling between July and September. The relationship weakens further south (Tamba, Saloum, see Fig. 2) with a longer rainy season, a vegetation composition which tends to stay green even though rainfall quantity changes, and increasing human impact. This steep north-south gradient is further expressed in the increasing quantity of total biomass, tree cover, and mean integrated NDVI (see Table 1; Fig. 2). Figure 2 demonstrates that the interrelationships between annual rainfall, integrated NDVI, and total biomass are highly correlated (Table 2), providing evidences of ecological and climatic changes in the past decades in the Sahel region. The overall correlation of annual NDVI and rainfall with the leaf biomass of woody species is higher than with the herb biomass (Table 2).

\section{Trend analyses of NDVI, leaf biomass, and herb biomass}

Trend analysis of annual NDVI in the 1987-2013 period reveals a strong positive trend $(+36 \%, b=0.15)$, confirmed by observations of total biomass $(+34 \%, b=43)$ and annual rainfall $(+40 \%, b=5)$ (Fig. 3). Tables 2 and 3; Fig. 3, and the temporal profiles (Appendix S2) demonstrate that the annual NDVI signal is a combination of both, leaf and herb biomass, with a coupling between the inter-annual variability in both annual leaf and herb biomass and the observed NDVI. However, the longterm NDVI signal in Fig. 3 clearly follows the positive change in leaf biomass of woody species which doubles over 27 years $(+103 \%, b=46)$, whereas the herb biomass data are characterized by large inter-annual variations $(r=-0.1)$ without any clear long-term trend. These variations are reflected in the temporal NDVI profile, but attenuated by the signal of leaf biomass, which is increasing steadily, with much lesser interannual fluctuations $(r=0.88)$ and parallel to NDVI $(r=0.85)$. This is true for all the studied ecoregions (Table 3 and Appendix S2), but the slopes of NDVI and leaf biomass increase along the north-south gradient with increasing tree cover, mean annual rainfall, and mean total biomass (Table 3; Fig. 4). Despite differences in tree cover, the magnitude of the NDVI slope (i.e. greening) does not significantly vary between the ferruginous (red points in Fig. 4, for colors see online version) and sandy Sahel (green points in Fig. 4, for colors see online version), but increases over the monitoring sites further south (Fig. 4). This implies that the order of magnitude of the NDVI greening is also covarying with the annual mean rainfall and the mean total biomass. However, the rather moderate correlations shown in Fig. 4 also imply that other factors
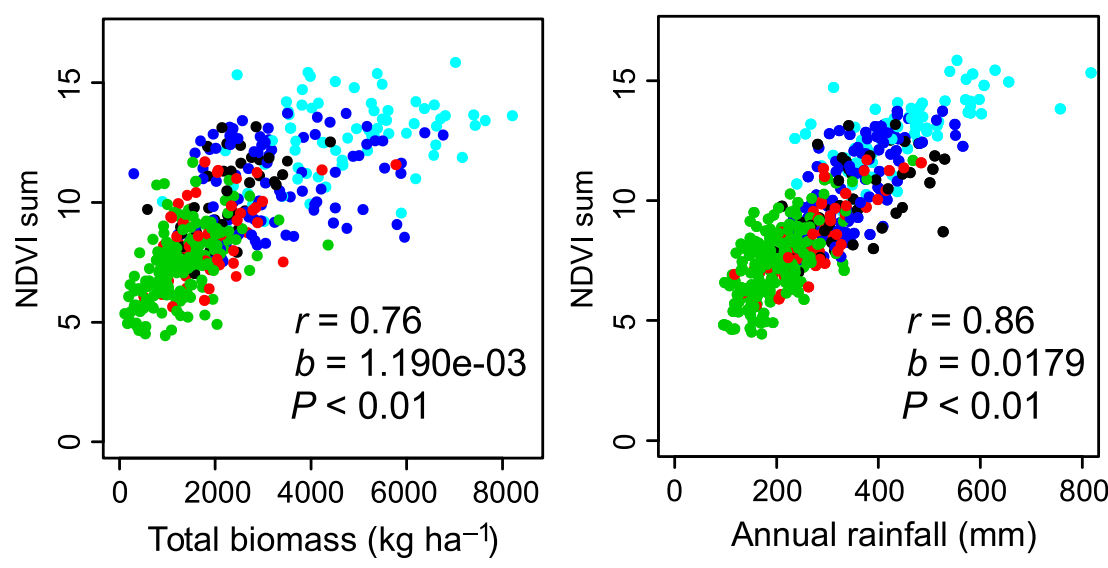

Fig. 2 Inter-relationships between annual rainfall, total biomass, and Normalized Difference Vegetation Index (NDVI) sum: scatterplots for 23 monitoring sites from 1987 to $2013(n=621)$ show agreement between the parameters. The provided statistics are the correlation coefficient $(r)$, the linear trend $(b)$, and its significance $(p)$. For color definitions, see Fig. 1. 
Table 2 Statistical relations between satellite (Normalized Difference Vegetation Index - NDVI sum and annual rainfall) and ground products (total biomass, herb biomass, and leaf biomass) for the period 1987-2013. The provided statistics are the correlation coefficient $(r)$, the linear trend $(b)$, and its significance $(p)$

\begin{tabular}{llll}
\hline & Total biomass & Herb biomass & Leaf biomass \\
\hline NDVI sum & $r=76, b=1.190 \mathrm{e}-03, p<0.01$ & $r=0.55, b=0.00135, p<0.01$ & $r=0.64, b=1.609 \mathrm{e}-03, p<0.01$ \\
Annual rainfall & $r=0.70, b=5.248 \mathrm{e}-02, p<0.01$ & $r=0.50, b=5.894 \mathrm{e}-02, p<0.01$ & $r=0.60, b=7.222 \mathrm{e}-02, p<0.01$ \\
\hline
\end{tabular}

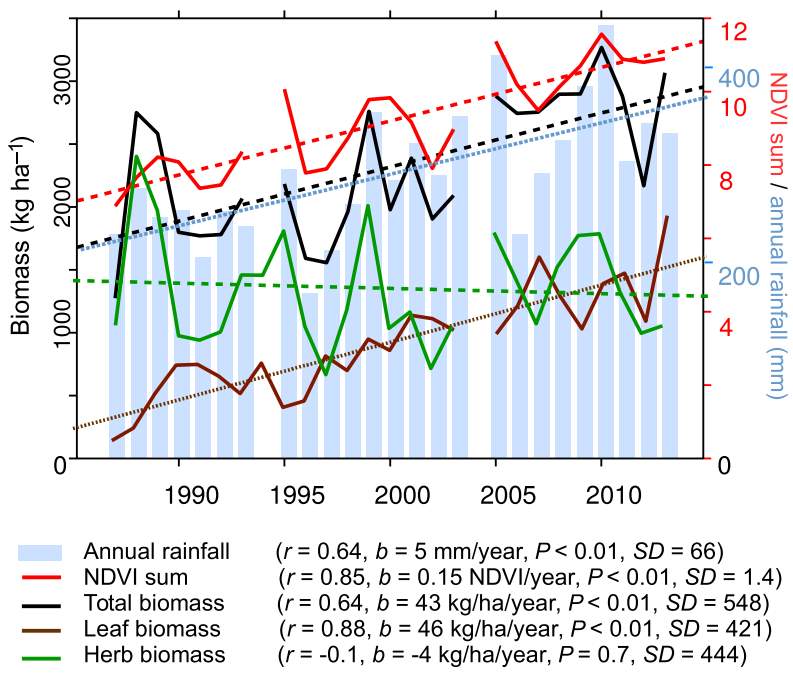

Fig. 3 Temporal profiles (1987-2013) of 23 monitoring sites demonstrate a positive, significant and consistent long-term trend (expressed as linear regression lines) of annual rainfall, Normalized Difference Vegetation Index (NDVI) sum, total biomass, and leaf biomass. Moreover, no clear trend is observed regarding herb biomass. The provided statistics are the correlation coefficient $(r)$, the linear trend $(b)$ and its significance $(p)$ and the standard deviation (SD). Additional statistics per ecoregion are provided in Table 3.

contribute to the magnitude of the overall NDVI greening (e.g. species composition and species-specific translation of biomass to annual NDVI, soil, human impact, patchiness in inhomogeneous mixed pixels, scale issues). Although determining the sources of spatial differences in the magnitude of greening is rather complex, Fig. 3 demonstrates that long-term changes in leaf biomass clearly determine the significant positive longterm trend observed in annual NDVI. These findings support our hypothesis, identifying trees as the driver of the positive NDVI trend and the dominant source of the greening phenomenon.

\section{Local vegetation characteristics}

Not only rainfall has significant impact on spatial variability of biomass production. Variations induced by soil and species composition are often neglected as explaining variables. Figure 5 exemplifies the temporal profiles of leaf biomass for two distinct different soil types (ferruginous and sandy monitoring sites). Leaf biomass profiles consistently show a strong increase over 27 years, but with significant variations between the two ecoregions, despite a similar amount of annual precipitation. The increment of leaf biomass on deep sandy soils is steady and stable $(r=0.87)$ and the effects of dry years are tempered (Brandt et al., 2014b). On shallow ferruginous soils, inter-annual fluctuations of leaf biomass are much larger $(r=0.58)$, caused by the poor water holding capacity and high runoff of shallow lateritic soils and the different composition of woody species, compared to the Sandy Ferlo (Brandt et al., 2014b). Sandy soils are dominated by a sparse cover $(5 \%)$ of the resilient

Table 3 Spatial variability of trend analysis: 23 monitoring sites are separated into the five different regions. The provided statistics are the correlation coefficient $(r)$, the linear trend $(b)$ and its significance $(p)$ and the standard deviation (SD) for herb and leaf biomass $\left(\mathrm{kg} \mathrm{ha}^{-1}\right)$ and Normalized Difference Vegetation Index (NDVI) sum over the period 1987-2013

\begin{tabular}{|c|c|c|c|c|c|c|c|c|c|c|c|c|}
\hline \multirow[b]{2}{*}{ Region } & \multicolumn{4}{|c|}{ Herb biomass } & \multicolumn{4}{|c|}{ Leaf biomass } & \multicolumn{4}{|c|}{ NDVI sum } \\
\hline & $r$ & $b$ & $p$ & SD & $r$ & $b$ & $p$ & SD & $r$ & $b$ & $p$ & SD \\
\hline Sandy Ferlo & 0.09 & 5 & 0.6 & 411 & 0.9 & 25 & $<0.01$ & 202 & 0.8 & 0.11 & $<0.01$ & 1.1 \\
\hline Ferruginous Ferlo & -0.1 & -5 & 0.6 & 359 & 0.6 & 50 & $<0.01$ & 687 & 0.7 & 0.11 & $<0.01$ & 1.2 \\
\hline Boundou & -0.03 & -29 & 0.2 & 526 & 0.6 & 44 & $<0.01$ & 367 & 0.8 & 0.16 & $<0.01$ & 1.5 \\
\hline Saloum & -0.2 & -1 & 0.9 & 875 & 0.7 & 33 & $<0.01$ & 556 & 0.9 & 0.18 & $<0.01$ & 1.6 \\
\hline Tamba & -0.5 & -44 & 0.01 & 735 & 0.8 & 100 & $<0.01$ & 1021 & 0.9 & 0.15 & $<0.01$ & 1.3 \\
\hline
\end{tabular}



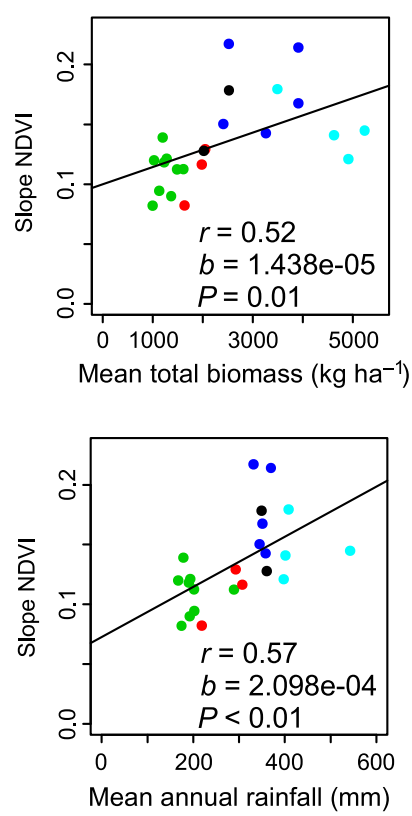

Fig. 4 These scatterplots show the relation of the Sahel greening (Normalized Difference Vegetation Index - NDVI slope) with mean annual rainfall and mean biomass present at the 23 monitoring sites. The provided statistics are the correlation coefficient $(r)$, the linear trend $(b)$, and its significance $(p)$. For color definitions, see Fig. 1.

evergreen and semi-deciduous species Balanites aegyptiaca, Boscia senegalensis, and Acacia raddiana, whereas deciduous species such as Pterocarpus lucens, Guiera senegalensis, and Combretum glutinosum prevail on ferruginous soils in a much denser cover (17\%) (Table 1). These species drop their leaves in the dry season and are vulnerable to rainfall variability. Monitoring of woody species in situ data over 30 years indicates a shift to more robust, evergreen, and semideciduous species on sandy soils (especially B. aegyptiaca and $A$. raddiana increase or are stable), with many deciduous species declining or locally vanishing (e.g. Sclerocarya birrea, Sterculia setigera, Adansonia digitata, C. glutinosum, Grewia bicolor, and Ziziphus mauritiana). In general, a decrease in biodiversity can be observed with 11 of 16 woody species declining either in the Sandy or Ferruginous Ferlo (Fig. 5 and Appendix S3). On sandy soils, 11 woody species declined in abundance and only one increased (A. raddiana) (Fig. 5). The Ferruginous Ferlo shows a larger figure with stable conditions (9). However, also this region has seen a decline/increase of $5 / 2$ woody species, respectively. The pattern is similar to the Sandy Ferlo, with A. raddiana and B. aegyptiaca increasing, and S. birrea, G. bicolor, S. setigera, and Combretum aculeatum decreasing. The abundance of Acacia senegal, Acacia seyal, A. digitata, B. senegalensis, C. glutinosum, Combretum micranthum, and G. senegalensis is stable between the surveys of 1983 and 2013. Tree mortality among many deciduous trees on ferruginous soils was high during the droughts in the 1980s (Tappan et al., 2004). Thus, the negative slope of herb biomass (Table 3) and the steep positive slope of leaf biomass in the Ferruginous Ferlo (Fig. 5) imply that the greening observed in NDVI sum (Table 3; Fig. 3) is caused
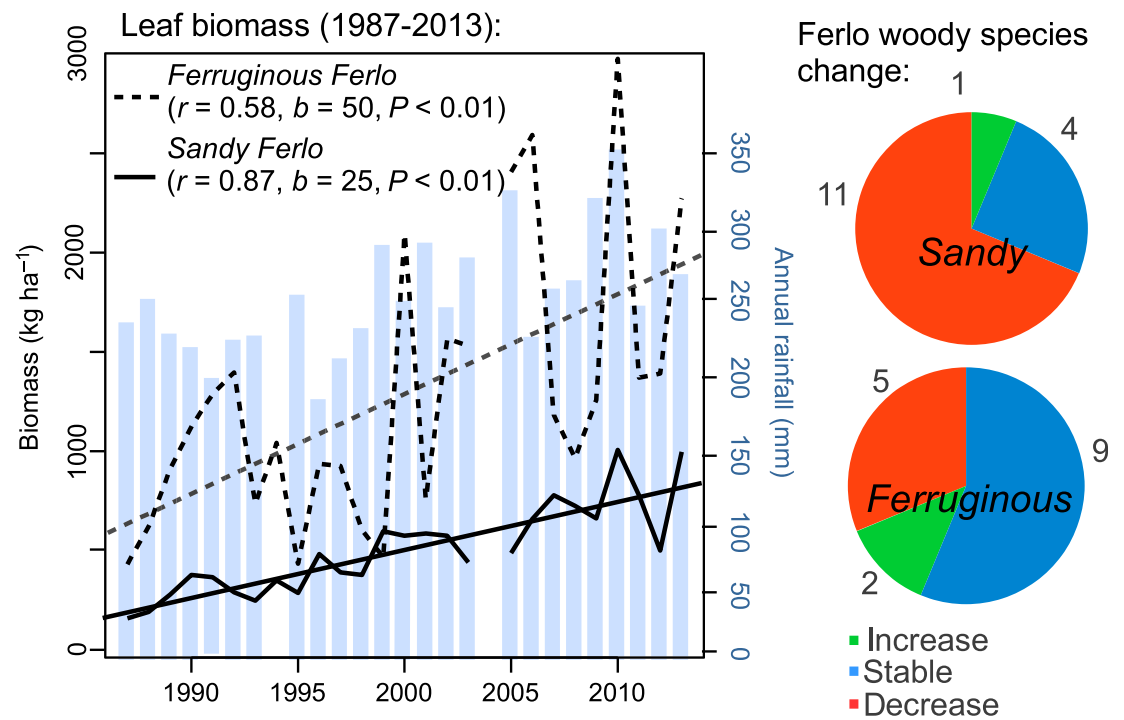

Fig. 5 Woody vegetation change: the temporal profiles show the leaf biomass of the sandy and ferruginous Ferlo. Although the rainfall regime is similar, the soil and vegetation composition has a significant impact on the slope, the leaf biomass production, and interannual variability. The provided statistics are the correlation coefficient $(r)$, the linear trend $(b)$, and its significance $(p)$. The pie charts on the right show a drastic shift in biodiversity of woody species from 1983 to 2013, especially in the Sandy Ferlo. 
by a recovery/spreading of only few species (especially A. raddiana and B. aegyptiaca), while others declined (e.g. G. bicolor, S. setigera, S. birrea). For more details, see Appendix S3.

\section{Discussion}

Data uncertainties and the influence of local factors

Estimating biomass using allometric models can lead to uncertainties on applied conversion factors and may not always give the most reliable results. In this study, the consistently collected data help to reduce variations which occur when measuring with different methods. Moreover, the relationship between NDVI and biomass data is not without bias. A generally higher correlation is prevented by patchiness in inhomogeneous mixed pixels, scale differences between the two datasets, uncertainties in both data sources (see Diouf \& Lambin, 2001; Brandt et al., 2014c), and a species-specific relation between greenness detected by NDVI and produced biomass (Mbow et al., 2013).

Only a limited number of biomass surveys exist in the Sahel (Mbow et al., 2013; Dardel et al., 2014a,b; Centre de Suivi Ecologique, 1996). Existing databases are not enough to rigorously assess the role of trees vs. herbs on the observed greening trend. Our stratification into different ecoregions located in Senegal shows the sensitivity of ecosystems regarding varying biomass production. This is further supported by a study from Dardel et al. (2014b), who observed a positive trend of herb biomass in northern Mali, despite the absence of a denser tree cover. Thus, a wider spatial coverage of biomass data encompassing many ecological areas for many years could bring improvements and reduce data uncertainties.

Spectral information has been interpreted with a range of assumptions on vegetation dynamics as a function of rainfall, making many studies difficult to compare (Hein et al., 2011). The complexity of the ecological processes driving the response of the Sahelian vegetation to rainfall variation requires disaggregated data on tree and herb biomass. Also, topographic and soil variations increase the variability and uncertainties in aggregated information, reflected in coarse satellite data (Hiernaux et al., 2009a,b; Hein et al., 2011; Brandt et al., 2014c). Additionally, the mixed spectral information of a pixel varies with the tree density. A dense tree cover hides the herbaceous layer and produces a different NDVI signal as compared to a sparse tree cover. Finally, satellite and rainfall products vary in resolution and quality, making the choice of the data an important factor (Samimi et al., 2012; Brandt et al., 2014c).
Furthermore, it is important to consider the grazing level and agricultural practices that add to the complexity of spatial variation of biomass production through the selection process of species or human pressures (Miehe et al., 2010; Hiernaux et al., 2009b; Haberl et al., 2007). By considering ecological zones with varying human influence, this study tried to identify the local responses of climate variability in relation to ecosystem characteristics. In the Sahel, patchiness of vegetation distribution exists on the ground at the local scale, which will not be captured at the regional scale, but are important for the distribution of biomass yield over time and space (Hiernaux et al., 2009a,b; Rasmussen et al., 2011). This patchiness affects mostly woody plants (ranging from sparse to dense cover) depending on soil and topography. In Mali, for example, Hiernaux et al. (2009a) found that tree mortality varies widely from sandy soils to clayey soils located in depressions. They highlighted an increase in tree density in all local topographic units since 1985, a finding that concurs with the results of our study.

Primary production in the Sahel - what does the greening mean?

The Sahelian zone has been portrayed as a region, where various climate change impacts can clearly be singled out and studied in more details because of the highly dominant signal of climate factors in many land processes (e.g. Hiernaux et al., 2009b; Gonzalez et al., 2012). Some of the studies pointed to different directions in the resilience and adaptation to climate change, some very hopeful (Mortimore \& Adams, 2001), others quite pessimistic (Gonzalez, 2001). Recent scientific outcome demonstrated that the 1970s and 1980s dry conditions in the Sahel have been reversed by positive anomalies in rainfall during recent decades, leading to likely more biomass production. Most studies have been based on Earth observation using the rapid advances of remote sensing techniques and data (Fensholt et al., 2009, 2012). Yet, little efforts have been invested in including ground-based data collections over a long-term period (Mbow et al., 2014), and conclusions about a regional scale increment in biomass remain speculative.

While many studies pointed to the implications of land dynamics on livelihood (Levy et al., 2004; Nyong et al., 2007; Mertz et al., 2008; Reenberg et al., 2013), few highlighted the implications of increased biomass production on ecosystem health and carbon sequestration (Woomer et al., 2004; Luedeling \& Neufeldt, 2012). The existing contentions on land productivity in the Sahel are related to methods of calculation, assumptions for the studies or the scale of analysis, and these 
differences are closely linked to discipline-specific methodological traditions (Rasmussen et al., 2006). It seems clear that there is a recently observed regional trend over the last decades, showing a dual positive signal on rainfall and subsequently on vegetation greenness, as observed by satellite vegetation indices. While we used data of three different sources in this study, the applied datasets show a consistently strong increase in NDVI, biomass, and rainfall, thus confirming recent findings on the re-greening of the Sahel (Herrmann et al., 2005; Anyamba et al., 2014; Dardel et al., 2014b). A high correlation between rainfall and NDVI is further confirmed (Anyamba et al., 2014), explaining the positive trend observed in spectral indices, which again realistically reflect the increment in total biomass. By disentangling biomass trends into trees and herbs, no clear long-term trend could be detected regarding the short lasting herbaceous cover, in contrast to the study by Dardel et al. (2014b) in the northern Sahel of Mali, an area with very sparse tree cover. Rather, large inter-annual fluctuations were observed in herb biomass in all the studied regions in Senegal, with an overall insignificant but negative trend, in spite of increasing rainfall. These fluctuations in the short lasting annual herbaceous layer are caused by grazing pressure and a varying intra-annual distribution of rainfall known to favor different herbaceous species (Hiernaux et al., 2009b). The different annual and perennial herbaceous species are characterized by different leaf distributions and thereby by varying reflectances (Mbow et al., 2013), thus leading to large inter-annual variations in herbaceous biomass with no uniform impact on long-term NDVI trends. This is further demonstrated by Mbow et al. (2013), who discovered species with high satellite-measured NDVI but low in situ measured biomass production. On the contrary, trees are long-living, and our monitoring sites show a doubling of leaf biomass over 27 years. This is only possible with an overall increase in woody phanerophytes, which has been shown in case studies by Brandt et al. (2014a) and Hiernaux et al. (2009a) and demonstrates the resilience of Sahelian trees. Although mainly driven by rainfall, this increase in tree cover might be supported by increasing levels of atmospheric $\mathrm{CO}_{2}$, which contributes to a competitive advantage of trees, as studied by Bond \& Midgley (2012), Wigley et al. (2010), and Kgope et al. (2010). These studies observed an increasing tree cover in savannah ecosystems, regardless of land use practices - a finding which concurs with our study. Moreover, despite an overall increasing population in urban areas, a human factor might support the observed green-up. Note that for the particular case of the study area, migration to cities and abroad is generating remittances (Rasmussen \&
Reenberg, 2012; Romankiewicz \& Doevenspeck, 2015). Many households are not fully dependent on natural resources and parallel structural changes including new job opportunities can result in reduced pressure on ecosystems (Brandt et al., 2014a). At the same time, with the devolution of natural resources governance, local planning strategies are seeking at improved management systems including protected areas (Bolwig et al., 2011).

The relevance of this greening at local level and the possibility of tracking evidence of such greening at finer scales are important issues in bringing consistency along the scales of appraisal. Longer time period assessment of biodiversity at finer scales highlighted in many instances a negative trend in species composition, as a result of the severe droughts in the region, over the last four decades (Gonzalez et al., 2012; Herrmann \& Tappan, 2013; Brandt et al., 2014a). The results confirm this apparent opposition in ecosystem trend assessments, which can be a source of interesting convergence, as production and diversity can be mutually exclusive. This is particularly the case in the Sahel, where species selection related to drought or recently increasing rainfall can favor specific species with high climate plasticity and high productivity. Yet, instead of a higher biodiversity with low biomass, the recent trends seem to show a higher biomass production with lower biodiversity, compared to the drought of 1970s baseline. Only recent studies indicate that both climatic and anthropogenic factors are driving this shift. Higher temperatures and prolonged dry periods, in combination with grazing, browsing, and selective felling, have transformed large parts of the Sahel within the past 50 years (Tappan et al., 2004; Miehe et al., 2010; Brandt et al., 2014a).

An increase in plant biomass, induced by positive rainfall anomalies, caused the positive greenness trend observed in satellite data over the last three decades, providing evidence of the greening Sahel. The NDVI signal is a combination of both leaf and herb biomass contributions and can be strongly influenced by local species composition and dynamics. However, we demonstrated that tree species in the study area, which are more resilient to drought than herbs, bear the signal of the greening phenomenon. In contrast to herb biomass, the greening is consistent with leaf biomass of woody species which increased steadily over the studied period, indicating that trees have the higher footprint on long time series of vegetation indices and thus give the long-term trend its positive direction. The increase in greenness was not reflected in the dynamics of biodiversity which was found to decline over the study period. Scrutiny on the meaning of positive vegetation indices and biomass trends is needed when translating 
productivity proxies to livelihood and land management requirements. As land resources relate tightly to ecosystems services, we should avoid using unidirectional approaches - biomass or diversity. A combination of the two methods could advance our understanding on linking biomass production at landscape scales to disaggregated species composition, to account for multi-functionality and relative importance of ecosystem components.

Site conditions (soils and human activities) also control the influence of inter-annual climate fluctuations on biomass production. Thus, for a complete understanding of the Sahelian vegetation productivity changes over recent decades, future studies must consider also the livelihood adaptation in response to biomass changes, either through changes in land use (including farming or conservation activities) or increase of livestock density (as carrying capacity becomes higher). Deeper studies are needed to address these new challenges in land management in response to climate change and demographic pressure.

\section{Acknowledgements}

The authors thank the Centre de Suivi Ecologique, Dakar, (especially Abdoulaye Wele and Moussa Sall) for a great and fruitful collaboration over the past 4 years and for collecting and providing the biomass data, which is a unique dataset over such a long time. We further thank Lina Eklund and Sabine Miehe for helpful comments on the manuscript. Woody species data of 1983 were provided by courtesy of Gray Tappan, US Geological Survey, EROS Center, Sioux Falls. A. Verger is the recipient of a Juan de la Cierva postdoctoral fellowship from the Spanish Ministry of Science and Innovation. Parts of the study were financed by a research grant of the BMBF, the German Ministry of Education and Research, awarded to C. Samimi. Finally, we thank the two reviewers for very thorough reviews.

\section{References}

Anyamba A, Tucker CJ (2005) Analysis of Sahelian vegetation dynamics using NOAA-AVHRR NDVI data from 1981-2003. Journal of Arid Environments, 63, 596614.

Anyamba A, Small JL, Tucker CJ, Pak EW (2014) Thirty-two years of Sahelian zone growing season non-stationary NDVI3 g patterns and trends. Remote Sensing, 6 , 3101-3122.

Ayoub AT (1998) Extent, severity and causative factors of land degradation in the Sudan. Journal of Arid Environments, 38, 397-409.

Beck HE, McVicar TR, van Dijk AIJM, Schellekens J, de Jeu RAM, Bruijnzeel LA (2011) Global evaluation of four AVHRR-NDVI data sets: intercomparison and assessment against Landsat imagery. Remote Sensing of Environment, 115, 25472563.

Bolwig S, Rasmussen K, Hesse C, Hilhorst T, Hansen MK (2011) New Perspectives on Natural Resource Management in the Sahel. University of Copenhagen, Department of Geography and Geology, Copenhagen. SEREIN Occasional Papers, no. 17.

Bond WJ, Midgley GF (2012) Carbon dioxide and the uneasy interactions of trees and savannah grasses. Philosophical Transactions of the Royal Society B: Biological Sciences, 367, 601-612.

Brandt M, Romankiewicz C, Spiekermann R, Samimi C (2014a) Environmental change in time series - An interdisciplinary study in the Sahel of Mali and Senegal. Journal of Arid Environments, 105, 52-63.
Brandt M, Grau T, Mbow C, Samimi C (2014b) Modeling soil and woody vegetation in the Senegalese Sahel in the context of environmental change. Land., 3, 770-792.

Brandt M, Verger A, Diouf AA, Baret F, Samimi C (2014c) Local vegetation trends in the Sahel of Mali and Senegal using long time series FAPAR satellite products and field measurement (1982-2010). Remote Sensing, 6, 2408-2434.

Centre de Suivi Ecologique (1996) Contribution a L'analyse Statistique des Donnees sur la Production Primare des Parcours Naturels du Senegal (1987-1995). CSE, Dakar.

Cissé MI (1980) The browse production of some trees of the Sahel: relationships between maximum foliage biomass and various physical parameters. In: Browse in Africa (ed. LeHouerou HN), pp. 205-210. ILCA, Addis Ababa.

Dardel C, Kergoat L, Hiernaux P, Grippa M, Mougin E, Ciais P, Nguyen C-C (2014a) Rain-use-efficiency: what it tells us about the conflicting Sahel greening and Sahelian Paradox. Remote Sensing, 6, 3446-3474.

Dardel C, Kergoat L, Hiernaux P, Mougin E, Grippa M, Tucker CJ (2014b) Re-greening Sahel: 30 years of remote sensing data and field observations (Mali, Niger). Remote Sensing of Environment, 140, 350-364.

Diallo O, Diouf A, Hanan NP, Ndiaye A, Prevost Y (1991) AVHRR monitoring of savanna primary production in Senegal, West Africa: 1987-1988. International Journal of Remote Sensing, 12, 1259-1279.

Diouf A, Lambin EF (2001) Monitoring land-cover changes in semi-arid regions: remote sensing data and field observations in the Ferlo, Senegal. Journal of Arid Environments, 48, 129-148.

Dregne HE (2002) Land degradation in the drylands. Arid Land Research and Management, 16, 99-132.

Fensholt R, Sandholt I, Rasmussen MS, Stisen S, Diouf A (2006) Evaluation of satellite based primary production modelling in the semi-arid Sahel. Remote Sensing of Environment, 105, 173-188.

Fensholt R, Rasmussen K, Nielsen TT, Mbow C (2009) Evaluation of earth observation based long term vegetation trends-Intercomparing NDVI time series trend analysis consistency of Sahel from AVHRR GIMMS, Terra MODIS and SPOT VGT data. Remote Sensing of Environment, 113, 1886-1898.

Fensholt R, Langanke T, Rasmussen K et al. (2012) Greenness in semi-arid areas across the globe 1981-2007 — an Earth Observing Satellite based analysis of trends and drivers. Remote Sensing of Environment, 121, 144-158.

Fensholt R, Rasmussen K, Kaspersen P, Huber S, Horion S, Swinnen E (2013) Assessing land degradation/recovery in the African Sahel from long-term earth observation based primary productivity and precipitation relationships. Remote Sensing, 5, 664-686.

Gonzalez P (2001) Desertification and a shift of forest species in the West African Sahel. Climate Research, 17, 217-228.

Gonzalez P, Tucker CJ, Sy H (2012) Tree density and species decline in the African Sahel attributable to climate. Journal of Arid Environments, 78, 55-64.

Haberl H, Erb KH, Krausmann F et al. (2007) Quantifying and mapping the human appropriation of net primary production in earth's terrestrial ecosystems. Proceedings of the National Academy of Sciences, 104, 12942-12947.

Hein L, de Ridder N, Hiernaux P, Leemans R, de Wit A, Schaepman M (2011) Desertification in the Sahel: towards better accounting for ecosystem dynamics in the interpretation of remote sensing images. Journal of Arid Environments, 75, 1164 1172.

Herrmann SM, Tappan GG (2013) Vegetation impoverishment despite greening: a case study from central Senegal. Journal of Arid Environments, 90, 55-66.

Herrmann SM, Anyamba A, Tucker CJ (2005) Recent trends in vegetation dynamics in the African Sahel and their relationship to climate. Global Environmental Change Part A, 15, 394- 404.

Hickler T, Eklundh L, Seaquist JW et al. (2005) Precipitation controls Sahel greening trend. Geophysical Research Letters, 32, L21415.

Hiernaux P (1980) Inventory of the browse potential of bushes, trees and shrubs in an area of the Sahel in Mali: method and initial results. In: Browse in Africa (ed. Le Houerou HN), pp. 197-210. ILCA, Addis Ababa.

Hiernaux P, Diarra L, Trichon V, Mougin E, Soumaguel N, Baup F (2009a) Woody plant population dynamics in response to climate changes from 1984 to 2006 in Sahel (Gourma, Mali). Journal of Hydrology, 375, 103-113.

Hiernaux P, Mougin E, Diarra L, Soumaguel N, Lavenu F, Tracol Y, Diawara M (2009b) Sahelian rangeland response to changes in rainfall over two decades in the Gourma region, Mali. Journal of Hydrology, 375, 114-127.

Horion S, Fensholt R, Tagesson T, Ehammer A (2014) Using earth observation based dry season NDVI trends for assessment of changes in tree cover in Sahel. International Journal of Remote Sensing, 35, 2493-2515.

Huber S, Fensholt R, Rasmussen K (2011) Water availability as the driver of vegetation dynamics in the African Sahel from 1982 to 2007. Global and Planetary Change, 76, 186-195. 
Huffman GJ, Bolvin DT, Nelkin EJ et al. (2007) The TRMM multisatellite precipitation analysis (TMPA): quasi-global, multiyear, combined-sensor precipitation estimates at fine scales. Journal of Hydrometeorology, 8, 38-55.

Kgope BS, Bond WJ, Midgley GF (2010) Growth responses of African savanna trees implicate atmospheric $\left[\mathrm{CO}_{2}\right]$ as a driver of past and current changes in savanna tree cover. Austral Ecology, 35, 451-463.

Levy PE, Cannell MGR, Friend AD (2004) Modelling the impact of future changes in climate, $\mathrm{CO}_{2}$ concentration and land use on natural ecosystems and the terrestrial carbon sink. Global Environmental Change, 14, 21-30.

Luedeling E, Neufeldt H (2012) Carbon sequestration potential of parkland agroforestry in the Sahel. Climatic Change, 115, 443-461.

Maidment RI, Grimes DIF, Allan RP, Greatrex H, Rojas O, Leo O (2013) Evaluation of satellite-based and model re-analysis rainfall estimates for Uganda: evaluation of rainfall estimates for Uganda. Meteorological Applications, 20, 308-317.

Mbow C, Fensholt R, Rasmussen K, Diop D (2013) Can vegetation productivity be derived from greenness in a semi-arid environment? Evidence from ground-based measurements. Journal of Arid Environments, 97, 56-65.

Mbow C, Fensholt R, Nielsen TT, Rasmussen K (2014) Advances in monitoring vegetation and land use dynamics in the Sahel. Geografisk Tidsskrift-Danish Journal of Geography, 114, 84-91.

Mertz O, Mbow C, Reenberg A, Diouf A (2008) Farmers' perceptions of climate change and agricultural adaptation strategies in rural Sahel. Environmental Management, 43, 804-816.

Miehe S, Kluge J, Von Wehrden H, Retzer V (2010) Long-term degradation of Sahelian rangeland detected by 27 years of field study in Senegal. Journal of Applied Ecology, 47, 692-700.

Mortimore MJ, Adams WM (2001) Farmer adaptation, change and crisis in the Sahel. Global Environmental Change, 11, 49-57.

Nyong A, Adesina F, Elasha BO (2007) The value of indigenous knowledge in climate change mitigation and adaptation strategies in the African Sahel. Mitigation and Adaptation Strategies for Global Change, 12, 787-797.

Olsson L, Eklundh L, Ardö J (2005) A recent greening of the Sahel-trends, patterns and potential causes. Journal of Arid Environments, 63, 556-566.

Prince SD, De Colstoun EB, Kravitz LL (1998) Evidence from rain-use efficiencies does not indicate extensive Sahelian desertification. Global Change Biology, 4, 359 374 .

Rasmussen LV, Reenberg A (2012) Land use rationales in desert fringe agriculture. Applied Geography, 34, 595-605.

Rasmussen K, Nielsen TT, Mbow C, Wardell A (2006) Land degradation in the Sahel: an apparent scientific contradiction. In: Natural Resource Management in Sahel - Lessons Learnt, (ed. Møllegaard M), pp. 37-43. Occasional paper: SEREIN, SahelSudan Environmental Research Initiative.

Rasmussen MO, Göttsche F-M, Diop D, Mbow C, Olesen F-S, Fensholt R, Sandholt (2011) Tree survey and allometric models for tiger bush in northern Senegal and comparison with tree parameters derived from high resolution satellite data. International Journal of Applied Earth Observation and Geoinformation, 13, 517-527.
Rasmussen K, Fensholt R, Fog B, Rasmussen LV, Yanogo I (2014) Explaining NDVI trends in northern Burkina Faso. Geografisk Tidsskrift-Danish Journal of Geography, $114,17-24$

Reenberg A, Maman I, Bouzou Moussa I, Fog B (2013) Land saturation in SE Niger: triangulating qualitative and quantitative information for critical assessment of land use trajectories. Land, 2, 508-533.

Romankiewicz C, Doevenspeck M (2015) Climate and mobility in the West African Sahel: conceptualizing the local dimensions of the environment and migration nexus. In: Grounding Climate Change. Contributions from the Social and Cultura Sciences, (eds Greschke H, Tischler J), pp. 79-100. Springer, Dordrecht.

Sagna P (2007) Caractéristiques climatiques. In: Atlas de l'Afrique. pp. 66-69. Editions Jeune-Afrique, Sénégal.

Samimi C, Fink A, Paeth H (2012) The 2007 flood in the Sahel: causes, characteristics and its presentation in the media and FEWS NET. Natural Hazards and Earth System Sciences, 12, 313-325.

Seaquist JW, Hickler T, Eklundh L, Ardö J, Heumann BW (2009) Disentangling the effects of climate and people on Sahel vegetation dynamics. Biogeosciences, 6, 469477.

Tappan G, Sall M, Wood E, Cushing M (2004) Ecoregions and land cover trends in Senegal. Journal of Arid Environments, 59, 427-462.

Tucker CJ, Vanpraet C, Boerwinkel E, Gaston A (1983) Satellite remote sensing of total dry matter production in the Senegalese Sahel. Remote Sensing of Environment 13, 461-474.

Tucker CJ, Vanpraet CL, Sharman MJ, Van Ittersum G (1985) Satellite remote sensing of total herbaceous biomass production in the Senegalese Sahel: 1980-1984. Remote Sensing of Environment, 17, 233-249.

Wigley BJ, Bond WJ, Hoffman MT (2010) Thicket expansion in a South African savanna under divergent land use: local vs. global drivers? Global Change Biology, 16, 964-976.

Woomer P, Tieszen L, Tappan G, Touré A, Sall M (2004) Land use change and terrestrial carbon stocks in Senegal. Journal of Arid Environments, 59, 625-642.

\section{Supporting Information}

Additional Supporting Information may be found in the online version of this article:

Appendix S1. Illustrations of study sites covering the five ecoregions.

Appendix S2. Spatial variability of trend analysis.

Appendix S3. Abundance and changes of woody species. 